\title{
1 \\ LANGUAGE EDUCATION POLICY IN ASIA
}

\section{An overview}

\author{
Andy Kirkpatrick and Anthony J. Liddicoat
}

\section{Introduction}

Language education polices are a form of human resource development planning (Kaplan \& Baldauf, 1997) that operate to develop language abilities that a society identifies as important for social, economic, or other objectives. They make statements about which languages will be included in education and the purposes for which those languages will be taught and learned. Policies therefore project an imagined future linguistic situation and make provisions to bring this into existence (Liddicoat, 2013). Understanding such policies is important for understanding how authoritative institutions such as governments and education systems construct the future possibilities for languages within their jurisdictions and attempt to shape emerging linguistic ecologies. The goal of this book is to understand language policies for education, how they have evolved over time, and what they have to say about the future of linguistic diversity in this vast region. The focus of the book is on explicitly stated language policies; that is, policies that are enshrined in various forms of language legislation, policy documents, curricula, and other educational texts. Such policies are inevitably accompanied by implicit policies, which equally shape language practices and can contribute significantly to what happens educationally (Spolsky, 2004). As public statements of governments' intentions and values in relation to language, explicit policies' documents have a particular place within the policy context as they are "explicit, tangible and authoritative statements of policy positions and as such can form a useful focus for study" (Liddicoat, 2013: 4).

This book aims to examine language education policy over an extensive region in order to foster a comparative perspective on how language is included in education and the forces that shape this both within and across nations. We have chosen to focus on Asia as the largest land mass on earth, with the largest proportion of the human population, and the greatest linguistic diversity. Given the demographic and linguistic significance of this region, it represents a significant site for language policy development.

The political geography of Asia is in many ways arbitrary as the geological region does not coincide neatly with the political, linguistic, and cultural realities of the region. In fact, Asia is itself an invention of Europe and European geography that has been reproduced over time (Markovits, 2013; Noor, 2014; Said, 1979). Both the grouping of nations, societies, and cultures together as Asia and the separating them out from others are discursive acts that are problematic 
given the reality of social, cultural, economic, and other relations both within the continent of Asia and across continental boundaries. A neat division of the political and social world into continents is ultimately problematic given the realities of a vast land bloc incorporating Europe, Asia, and Africa with on-going contacts and demographic and economic flows across geological boundaries. In framing this book, we have chosen to construct the idea of Asia in a particular way and have excluded from consideration some areas that are geographically normally considered as a part of Asia: Russia and the Middle East. While Russia is the largest country on the continent of Asia, we have chosen not to include Russia in this volume as we felt that the political and cultural influences and the political elites that shape Russian language education policy are more strongly based in Europe than they are in Asia. The Middle East, or Western Asia, has many linguistic and cultural connections with Central and Southern Asia, but also with Northern Africa. We felt that Western Asia would be much better considered together with Africa in view of the significance of Arabic and Islam across the region.

This book is presented as a series of polity studies of the Asian region that examines the ways that the dynamics of the various languages present in each context play out in the field of education. The studies are grouped geographically for convenience: East Asia, South East Asia, South Asia, and Central Asia. However, this grouping, like any other, is somewhat arbitrary and can suggest a coherence that is not in fact evident in the local realities of the policies under consideration and can also obscure realities that cut across these geographical divisions. In addition to the polity chapters, two chapters with a supra-local focus have also been included to highlight issues that tend to be obscured in broad considerations of a polity. These issues are minority language learning and mother tongue education. These are two issues that tend to be peripheral, or even absent, in much of the policy work in the region, although significant developments have been occurring in both that deserve special attention.

All of the polity chapters in this book present information about how education policies address issues relating to national languages, indigenous languages, and other languages, of which English forms a special case. Below, we have attempted a synthesis of the policy directions found within the region in each of these areas as a way of characterising language education policy in Asia.

\section{National languages}

Most of the countries of Asia were colonised and only gained their independence in the second half of the 20th century and so language in education planning in many countries has to be understood in the context of earlier colonial policies and the need for nation-building work post-independence. Different countries in the region had very different histories of colonialism. In some places in South Asia and South-East Asia, European powers began to establish a colonial presence from the 16th century, while in other countries, colonial history is much more recent. Asia was a target of most of the European colonial powers, with the UK, France, Portugal, the Netherlands, and Russia all carrying out imperialist projects in the region. Spain held power in the Philippines until the 19th century, but from then had no colonial presence in the region. In some places (notably in India, the Philippines, and Indonesia), colonial history is complex with changes in the colonial power over time. In addition to the European colonisers, Japan was also an active colonial power, establishing colonies in the Korean peninsula and Taiwan in the late 19th and early 20th centuries. The US replaced Spain in the Philippines from 1898 and Indonesia occupied Timor Leste at the end of Portuguese control in 1975. Most of the colonising powers established overseas colonial regimes of various types but the case of Russian colonialism in Central Asia involved instead incorporation of territory into the Russian state. 
In all, very few countries escaped colonisation, with Thailand, Mongolia, Nepal, and Japan the exceptions. China, although not fully colonised, ceded territory to Portugal (Macau), the UK (Hong Kong), and Japan (Taiwan and briefly Manchuria). Bhutan and Afghanistan, although not formally annexed, were subject to strong influence from the UK, especially in foreign affairs.

The colonial regimes normally used the colonisers' language as the language of administration and established educational programmes using the colonial language as the medium of instruction. This meant that at the time of independence, there were established elites in most countries who were educated in the colonial language and the main education systems functioned in the colonial language. At independence, much of Asia, unlike Africa, rejected the use of colonial languages as official languages of the new states and chose local languages. Usually, the newly independent states chose a single language as the official variety and adoption of this language by all citizens was seen as central to the building of national identity. In a small number of countries, multiple local languages were given official recognition (e.g. India, Singapore, Sri Lanka) usually in contexts of complex linguistic diversity. Afghanistan recognised both Pashto and Dari as official.

In some cases, the former colonial language was maintained as an official language, alongside local languages (e.g. English in Singapore, India, Philippines; Portuguese in Timor Leste; Russian in Kyrgyzstan). After their return to China, both Hong Kong and Macau adopted policies that continued the use of the former colonial language (English and Portuguese) alongside Cantonese. Hong Kong formulates its policy as official trilingualism (Cantonese, English, and Mandarin) and biliteracy (English and Chinese). The reasons for keeping colonial languages are complex. In some cases, the colonial language has been viewed as important as a lingua franca that facilitates communication between ethnic groups within the nation (e.g. English in Singapore and India) and may play this role as a language not closely linked to a particular ethnic group. In Central Asia, Russian has been maintained in recognition of the large numbers of ethnic Russians present in the country but may also be considered as having a lingua franca function for interethnic communication. In some cases, although not official, a former colonial language may be given special status as a language of interethnic communication (e.g. English in Sri Lanka, Russian in Tajikistan). Former colonial languages may also be maintained as being more suited to international communication than the local official language(s).

For most of the countries in the region, literacy and internal language spread policies were important for educational planning, especially in newly independent states. At the beginning of the 20th century few countries in the region, whether colonies or not, had high levels of literacy and in colonised nations, literacy had normally been developed in the colonial language. Many of the countries of the region have therefore given a great deal of attention to literacy development in the official language, with many raising literacy levels very substantially since the mid-20th century. Internal language spread policies involved increasing use of the spoken variety among those who did not speak it as a first language. Coupled with the focus on official language literacy, this meant that education of linguistic minorities has mainly been conceptualised in terms of developing language and literacy skills in the official variety. In this context, the official language has typically been the sole language of schooling and other languages at best have been given only marginal roles.

Although in most countries in the region the medium of instruction is the sole official language of the state, there are complexities around the medium of instruction policy in some parts of Asia. In some places where there are multiple official languages, these languages have not always been treated equally. For example, in Singapore only one language, English, is used as the normal medium of instruction for the majority of the curriculum, with the other official languages having the more marginal role of subjects in the curriculum. In Central Asian republics 
such as Kazakhstan and Kyrgyzstan, the emphasis on internal spread of Kazakh and Kyrgyz means that Russian is much less frequently used as the main medium of instruction and access to Russian schools may be limited. In Macau, Portuguese, although official, has a very marginal role in education compared to Chinese. In Hong Kong, medium of instruction is the focus of controversy with education in English medium schools considered of better quality and more desirable than education in Chinese medium schools. There has thus been substantial public pressure to expand English medium education at the expense of Chinese.

Language education policy in many parts of the region has been closely tied to the dissemination of corpus planning activities, such as standardisation, elaboration, and codification. In some countries, languages which had not previously been used in schooling or for other official functions came to be used as official languages and required substantial corpus development, especially in academic domains. In many places, language planning agencies were established to undertake this corpus development work, which involved producing reference works such as grammars and dictionaries and pedagogical materials. In most countries this work was substantially the work of post-independence governments (e.g. India, Indonesia, Philippines) but in Central Asia significant work was carried out before independence as a result of the emphasis of the USSR government on the development of ethnic languages. For these countries, therefore, at independence there was substantial corpus planning work already completed and the languages had been to some extent integrated into the educational and national system, although usually dominated by Russian. In Central Asia, a key corpus planning issue has been whether to continue or break with the decisions of the Soviet era, especially in terms of script policy. The decision to replace Cyrillic with the Latin in Turkmenistan and Uzbekistan has had significant consequences for education as it has meant that existing educational resources can no longer be used, and a significant investment is needed in new materials. Even in countries with wellestablished language traditions, there has been some corpus development work with a direct impact on education in the national language, such as the simplification of characters in China, the establishing of approved kanji lists in Japan, and the replacement of Chinese characters by hangul in both North and South Korea.

Overall in the Asian region, language education policy has been used as a vehicle for nationbuilding and for attempting to establish a shared sense of national identity through the development of a common language. This appears to have been a central concern of policies both in countries created through colonialism, which may not have had an established national identity prior to colonisation and independence and also of more established countries that have not been subject to colonisation. Multilingual education policies are much less frequently found. This indicates that the region has been strongly influenced by the post-Enlightenment one nation - one language ideology (Liddicoat \& Heugh, 2014; May, 2012), which was exported from Europe during the colonial period. Language policy has thus tended to consider linguistic diversity as potentially problematic for national unity and national cohesiveness.

\section{English}

Along with the promotion of their respective national languages, the polities covered in this

AU: you used 'Mandarin' earlier, would you like to make this consistent or do you prefer the distinction? Handbook also privilege English as the first 'other' language to be taught in schools. As the chapters show, the demand for English and English medium education is influencing the educational agenda across the region. Hong Kong provides a good example. As noted above, the government's aim is to produce citizens who are trilingual in Cantonese, Putonghua, and English and biliterate in Chinese and English. However, the fact that six of the eight government-funded universities are English medium, as well as all the private universities, means that 
parental demand for English is such that many Chinese medium secondary schools are teaching more and more classes in English and fewer in Chinese. Bangladesh provides another example where English is challenging the national language, Bangla. As the authors of the chapter on Bangladesh argue, the changes in language policy in general and English language policy in particular can be read as a neoliberal narrative in a globalised world i.e. how a nation with a strong sense of linguistic nationalism at birth has gradually opened itself to English and has given space to supra-national and sub-national entities that have promoted English. There is a sense of irony here, as Bangladesh broke away from Pakistan and was established as an independent nation state on the basis of language, Bangla. In the early years of Bangladesh's existence, English had only limited scope but was introduced into the first years of primary school in the early 1990s. The years since then have seen an exponential growth in the teaching of English and it has become the medium of instruction in all private schools. This move towards English medium of instruction is also seen at university level, both private and government. This has led the government to insist that English medium schools also teach classes in Bangla and the Education Act of 2016 makes Bangla and Bangladesh studies a compulsory part of the curriculum. However, if the state can be seen to maintain some sort of balance between Bangla and English in the public sector, this balance does not appear to be relevant for the non-state sector. Bangla appears to have been undermined in English medium schools and private universities. This pattern of private education providing English medium programmes and the state providing education through the national language can be determined in many of the polities reported on here. The increase in the parental demand for and popularity of an English medium education can also be determined. For example, in Nepal, the expansion of English as a medium of instruction in public schools exemplifies how neoliberal private schools shape the public discourses and policies of language education.

Vietnam provides another example where the national language is seen to be under threat from English. As the authors of the chapter on Vietnam point out, although Vietnamese remains the most important language of education at all levels, the rapidly increasing number of private education institutions and universities have adopted English as a medium of instruction (EMI). This increased role of English is seen to threaten Vietnamese as EMI students report identifying less with Vietnamese culture with the result that the government has ruled that all students attending private educational institutions must take compulsory courses in Vietnamese language and culture.

Language education policy in Bhutan is solely focussed on the promotion of Dzongkha as the national language and English. Indigenous languages other than Dzongkha currently have no place in the education system. It is expected that children will acquire their home language at home. The only languages included in school contexts are the national language and English. Thus, at kindergarten level, Dzongkha is the sole medium of instruction and English is introduced as a subject. At later primary school levels, the role of English is expanded with English becoming the medium of instruction in increasing, but unspecified proportions over the duration of primary education until in Grade 4, English replaces Dzongkha as the language of instruction, with Dzongkha language and literature continuing as a subject. This situation is then continued through secondary school and in tertiary education. Bhutan thus provides an extreme example of the trends which can be identified by analysing the language policies and practices encountered in the Handbook. The national language, in this case Dzongkha, and English represent the two main languages of education, with other indigenous languages playing no part.

As will be discussed below, the promotion of English leads to the neglect of indigenous languages within the education systems. But it also leads to heightened divisions between the haves 
and have nots, often realised by the haves buying private English classes and/or buying private English medium education and creating a marked distinction between private and public/state education; the English taught in state education is often poorly taught, and, in many cases not taught at all, despite government policy, because there are no teachers to teach it. For example, as the authors of the Myanmar chapter show, while technically university departments are allowed to use either English or Burmese, or some combination of the two, by long tradition, a majority of departments across the country use English as the sole medium of instruction and many require that examinations and theses be written only in English. The central problem with this proposition is the low English levels among both teachers and students, and a lack of access to trained English teachers. At a conference on multilingual policy in Mandalay in February 2016, Thant Sin Aye provided the results of her survey research of faculty and students across universities in Burma which showed that the majority would prefer to teach and be taught in Burmese, even if textbooks remain in English.

Cambodia has recently introduced English from Grade 4 of primary school. However, many teachers who are expected to teach English have very low or no skills in the English language. As a result, in practice, many schools do not include English in their teaching syllabus. A policy to include English as a required school subject is in place, but it is not practiced in most primary schools of the country. This 'gap' between policy and practice can be seen in many contexts throughout the region.

China has more students learning English than anywhere else in the region. English is introduced as a compulsory subject from Grade 3. In many cases, however, English is introduced even earlier, with private kindergartens catering to middle class demand for an English education for their children. Again, we see a divide between the wealthy who can afford special and extra English classes for their children and those who cannot. This often takes the form of an urbanrural divide. The privileging of English together with the national promotion of Putonghua like many other countries, the PRC desires a unified and strong country and to that end the promotion of a national lingua franca is seen as essential - threatens local minority languages and other Chinese languages. History tells us that this could cause a rapid diminishing of minority languages and linguistic diversity and even social disturbance. Even a widely perceived 'safe' language with strong ethnolinguistic vitality such as Mongolian shows some signs of being endangered. Many dialects of Chinese also feel under threat.

Even in Central Asia, where Russian has continued to be the most widely taught additional language, the position of Russian is being challenged by an increasing demand for English. This situation reflects a more widespread historical trend in the region where English displaced other languages from educational systems during the second half of the 20th century. The primary motivator for the growth of English in the region has been the increasing globalised role of English and an ideological positioning of English as the language of modernisation and economic opportunity supported by the neoliberal agenda of education for economic utility (Davies \& Bansel, 2007; Piller \& Cho, 2013). The predominance of English in Asia is not only a feature of individual polities' policies, but is also supported by supra-regional bodies, most significantly ASEAN (the Association of Southeast Asian Nations). ASEAN's language policy has been one in which the languages of Asia have been excluded in favour of a single working language, English. The reach of this monolingual language policy has been further widened by the recent expansion of ASEAN as the ASEAN+3 to include China, Japan, and South Korea, at the end of 2015 (ASEAN, 2015). This regional grouping gives further impetus to the place of English in Asia, especially East Asia, and to the pragmatic, neoliberal rationale for a monolingual focus on English for communication outside the nation-state (Kirkpatrick, 2012; Kirkpatrick \& Liddicoat, 2017). 


\section{Indigenous languages}

The area under consideration is the most linguistically diverse region of the world. In Indonesia alone, there are some 700 languages. Yet it is rare to find indigenous languages being systematically taught as part of the education system. In almost all cases, indigenous languages are neglected, if not ignored. Where they are taught, they are taught either by religious institutions and/or depend on funding from NGOs. These are often pilot projects and seldom part of mainstream education.

Bangladesh provides an example of a place where the teaching of indigenous languages is dependent upon NGOs and external funding. The NGO, Building Resources Across Communities (BRAC), is the largest NGO in the world. In Bangladesh, BRAC owns 13,800 pre-primary schools with 400,072 students, and 22,971 primary schools with 681,794 students. BRAC also operates 1,635 ethnic minority schools in the south eastern region which provide multilingual education (involving indigenous languages, Bangla, and English) in which 40,175 minority students are enrolled. The authors of the Bangladesh chapter conclude that we may be witnessing an educational situation where the national language is losing ground to English and indigenous languages, albeit slowly, brought about by forces beyond state control.

India is one of the most linguistically diverse countries of this linguistically diverse region with some 800 languages being spoken. Languages in India constitute a hierarchical and pyramidal power structure of broadly three layers. English occupies the most powerful position in the hierarchy. Hindi and other major regional languages are in the middle layer of the hierarchy. The majority of languages, the indigenous, tribal, and minority languages, are in the lowest rung of the power hierarchy. This hierarchical system of power relationships between languages in India is characterised by a double divide, one between English and the major regional languages (English-Vernacular divide) and the other between the major regional languages and ITM languages (Vernacular-Other divide). In India, as in many of the other contexts discussed here, the rhetoric of language policy in education remains fractured between a political desire to promote the mother tongues and indigenous identities of the masses in a multilingual society and, at the same time, to cater to the growing popular craze for English. In this 'battle' between English and indigenous languages, English emerges on top, as the hegemonic role of English in Indian education has forced a monolingual orientation to education in a country where multilingualism is the social reality. There are, however, some efforts to promote a system of mother tonguebased multilingual education (MTBMLE). For example, the regional government of Odisha has introduced a mother tongue-based policy for tribal children in the state. Nevertheless, the authors of the India chapter conclude that indigenous languages are cumulatively ignored and neglected in education.

In contrast to one of the most linguistically diverse places covered in the Handbook, Cambodia is one of the least linguistically diverse, with Khmer being spoken by some $90 \%$ of the population and with 'only' 23 other languages being spoken. Although English is the first other language to be taught, being compulsory from Grade 4 of primary school, the lack of teachers and resources referred to earlier actually means that many Cambodian children are educated in a monolingual Khmer environment. With regard the indigenous languages, a 'Multilingual Education National Action Plan' (MENAP) was finalised in late 2015 and officially launched in March 2016 with some success. As of early 2016, more than 5500 children had studied in or were attending formal schools providing multilingual education, and 150 people have been trained as teachers in multilingual education. It is estimated that the number of multilingual education students will double by the end of 2018. Cambodia therefore represents an example of a country where the national language is dominant, where English is privileged as 
the first 'other' language to be taught in schools, but without the teachers or resources to implement the policy, but where some progress towards the adoption of MTBMLE is being made.

NeighbouringVietnam pays lip service to the teaching and learning of indigenous languages, but rigorously promotes Vietnamese as the medium of instruction. As the authors of the chapter on Vietnam note, the early enforcement of Vietnamese as the medium of instruction appears to disadvantage minority students as they have to acquire scientific knowledge in a language they are not yet proficient in. This has been reported to cause high dropout and failure rates among ethnic minority school-goers.

As a general rule, the almost universal drive to promote a single national language as a marker of national unity and identity runs counter to the promotion of indigenous languages. Governments may see the teaching and learning of indigenous languages as inimical to the project of promoting national unity and a nation state. The chapter on Thailand provides an example where the teaching and learning of indigenous languages is viewed with suspicion, especially in the south of the country, where Thai is the medium of instruction, even though Pattani-Malay is the mother tongue of the majority of the population. The Ministry of Education's rationale for learning Thai first centres on promoting national identity, national unity, and strengthening 'Thainess.' Nonetheless, the monolingual education system is generally seen as ineffective, with one-third of teenagers functionally illiterate. The insistence on using the national language as the medium of instruction, as is the case in the majority of the places covered in the Handbook, can result in poor educational outcomes for children whose mother tongue is not the national language.

Interestingly, the remoteness of an area may help preserve an indigenous language. As Koehler reports in her chapter on Indonesia, the vitality of local languages is affected by the size and location of the community of speakers, with large urban-based languages such as Javanese and Sundanese generally faring much better than smaller, rural-based languages such as Bantik. However, size and remoteness can be a saving grace for some languages (such as those of Sumbawa and Alor) as they have been somewhat protected from more dominant languages. At the same time however, Indonesian is increasingly a first language and this trend may be producing an increase in monolingualism amongst some groups.

While indigenous languages are, in the main, excluded from mainstream education, there are examples where governments are actively promoting a system of mother tongue-based multilingual education (MTBMLE). In the Philippines, for example, 19 indigenous languages have been gazetted to be taught as media of instruction for the first three years of primary school, with transition to the national language, Filipino, and English taking place in the later years of primary school. However, as Young (this volume) notes, last-minute changes to the policy were introduced, resulting in the discrepancy between what the proponents had initially agreed beforehand and the version that the President signed into law, prompting one wellknown proponent of MTBMLE, Ricardo Nolasco, to call the policy a 'castrated policy', as it only required the use of these indigenous languages as media of instruction for the first three years of primary school rather than throughout primary school as originally planned. At the same time, a lack of materials and funding means that many materials and resources have not been developed.The new system is also designed to make learning 'paperless.'Yet this paperless system makes access difficult especially in areas where Internet service is poor or non-existent. And, as Young also notes, there is no foreseeable addition to the 19 languages granted official MOI status in the mid- to long term. And it should also be noted that, while the use of 19 indigenous languages as media of instruction represents a significant change from the previous bilingual education policy whereby English acted as the medium of instruction for maths and science subjects and the national language, Filipino, for other subjects from Grade 1 of primary 
school, the Philippines is linguistically diverse with more than 170 languages spoken across the archipelago.

While many countries covered in this Handbook are in fact moving to provide some form of MTBMLE for children whose first language is not the national language, this is, as noted above, often funded by NGOs or religious institutions and takes the form of pilot projects. The Philippines national policy of MTBMLE provides an exception to this, but, as noted above, the MTBMLE policy in the Philippines is not without its problems. As Benson reports in her chapter, it has been estimated that $40 \%$, or 2.3 billion, of the world's people still lack access to instruction in a language they speak or understand and as Bradley notes in his, in all countries of mainland Southeast Asia, indigenous ethnic minority languages are largely excluded from the government education system as a consequence of policies in support of the national language. This means that indigenous ethnic minorities are in most cases greatly disadvantaged when they start school in the national language.

\section{Foreign languages other than English}

In Asia, foreign language education has become synonymous with the teaching and learning of English and other foreign languages have at best a minimal role in education, especially in schools. In some countries study of English as a foreign language is specified in local language policies, while in others the policy refers more generally to foreign language study. However, regardless of how the policy is framed, English has become the default language in all policies for foreign language teaching.

The exception to this broader trend is in Central Asia, where Russian has held at least some of its former position in those republics where it does not have official status. Kazakhstan, for example promotes Kazakh-Russian bilingualism and requires all students to study Russian and other republics also provide instruction in Russian as an additional language. The maintenance of Russian in the education systems of these countries is motivated by a number of factors including the practical need for Russian as an interethnic lingua franca, ongoing economic links between the Russian Federation and Central Asia, the political influence of Russia in the region and possibilities for cross-border mobility. Even in Central Asia, however, the position of Russian is challenged by English and the relative balance of English and Russian in education may change in future.

Although English dominates education, other languages are nonetheless present as foreign languages. In universities, a greater diversity of foreign languages is offered than in schools and the enrolments in these languages are greater than in schools, although often still marginal compared to the study of English. Much learning of foreign languages is thus undertaken in elective ab initio tertiary level programmes. In each polity, the number of languages available to learners at school or tertiary level is likely to be quite restricted, with high prestige European languages such as French, Spanish, and German tending to predominate, along with Chinese as the most widely taught Asian language. In many cases, the teaching and learning of these languages is supported by external language spread agencies such as the Alliance Française or the Confucius Institute. It is probable that political support from outside is more important for the presence of some of the languages available than local government language education policies. In Islamic countries, Arabic has maintained a position in schools, especially in religious schools, although it is less widely taught than English and is often taught only for the purposes of Qur'anic recitation or other religious uses.

The present dominance of English is the result of patterns of change in language education policy over the period since the end of the end of the Second World War. Early in the post-war 
period, there was a greater diversity of languages taught especially in schools and larger numbers of students studying them at both school and university. For example, in South Vietnam, French held a significant place in education, which was eventually lost to English. In Communist states, Russian as the prototypical language of the Communist movement was commonly taught as a foreign language in both schools and universities (e.g. in (North) Vietnam, North Korea, Mongolia, the People's Republic of China). The presence of Russian was, however, substantially eroded in favour of English from the 1990s following the collapse of the USSR, although English had begun to make an appearance even before this.

Most of the period since the Second World War has been characterised by an overall decline in the diversity and the amount of study of foreign languages other than English. Nonetheless, there seems to be some evidence that this decline may be halting at least in some countries and enrolments may be increasing in some foreign languages, for example in China where there has been some encouragement of more diversified foreign language learning by some regional governments. Although overall proportions of learners remain very small in comparison with English, there is thus some evidence that in future the movement to English-only foreign language education may be slowing.

\section{Summary}

In summary, the following trends emerge from this study of language policy and practice:

$\mathrm{i}$ the promotion of the respective national language as part of the drive to create the idea of a nation state and to promote national unity;

ii the promotion of English as the first 'other' language to be taught in schools as part of the neoliberal agenda in the drive to modernise and participate in globalisation;

iii the teaching of English is often unsatisfactory with a paucity of trained teachers with sufficient proficiency in English to be able to teach it;

iv an increasing division between public (national language as medium of instruction) and private (English medium of instruction) education which widens the gap between the 'haves' and the 'have nots';

$\mathrm{v}$ many children in the region are being taught in a language they do not understand and-thus failing at school;

vi there is a 'rhetorical' promotion of indigenous languages but, in practice, the teaching and learning of indigenous languages is left to NGOs, religious institutions, and mainly takes the form of pilot projects. The number of local languages being used in education remains a minute fraction of the total.

Taken together these trends suggest that the linguistic diversity of the region is threatened by policies which promote the respective national languages and English. However, more governments do appear to understand the benefits to be derived from mother tongue-based multilingual education and thus may promote the teaching and learning of a small number of indigenous languages. With few exceptions such as in the Philippines, however, bilingualism in the national language and English is becoming the common goal of language education throughout the region, but it should be stressed that only the middle classes successfully attain this goal. The lack of resources and the lack of suitably qualified and proficient teachers means that, in many cases, English is either poorly taught - and thus not learned - or not even taught at all, despite being a compulsory subject. This is heightening the division between the 'haves' and the 'have-nots.'There is little evidence for other forms of multilingualism as an educational 
goal, whether this is home language, national language, English, or national language, English, other foreign language. There is also little evidence for systematic support for the inclusion of indigenous languages as languages of education. The linguistic diversity of the region therefore looks under severe threat and the future of many local languages looks bleak.

\section{References}

ASEAN. (2015). ASEAN Economic Community blueprint. Jakarta:The ASEAN Secretariat.

Davies, B., \& Bansel, P. (2007). Neoliberalism and education. International Journal of Qualitative Studies in Education, 20(3), 247-259. doi:10.1080/09518390701281751

Kaplan, R. B., \& Baldauf, R. B. (1997). Language planning: From practice to theory. Clevedon, UK: Multilingual Matters.

Kirkpatrick, A. (2012). English as an international language in Asia: Implications for language education. In A. Kirkpatrick \& R. Sussex (Eds.), English as an international language in Asia: Implications for language education (pp. 29-44). Dordrecht: Springer Netherlands.

Kirkpatrick, A., \& Liddicoat, A. J. (2017). Language policy in Asia. Language Teaching, 50(2), 155-188.

Liddicoat, A. J. (2013). Language-in-education policies: The discursive construction of intercultural relations. Bristol, UK: Multilingual Matters.

Liddicoat, A. J., \& Heugh, K. (2014). Educational equity for linguistically marginalised students. In M. Bigelow \& J. Ennser-Kananen (Eds.), The Routledge handbook of educational linguistics (pp. 79-91). New York \& London: Routledge.

Markovits, C. (2013). L'Asie, une invention européenne? Monde(s), 3(1), 53-66. doi:10.3917/mond. 131.0053

May, S. (2012). Language and minority rights: Ethnicity, nationalism and the politics of language (2nd ed.). New York: Routledge.

Noor, F. A. (2014). The discursive construction of Southeast Asia in 19th century colonial-capitalist discourse. Amsterdam: Amsterdam University Press.

Piller, I., \& Cho, J. (2013). Neoliberalism as language policy. Language in Society, 42(1), 23-44. doi:10.1017/ S0047404512000887

Said, E. W. (1979). Orientalism. New York: Random House.

Spolsky, B. (2004). Language policy. Cambridge: Cambridge University Press. 